\title{
AKR1C1 controls cisplatin-resistance in head and neck squamous cell carcinoma through cross-talk with the STAT1/3 signaling pathway
}

Wei-Min Chang ${ }^{1}$, Yu-Chan Chang ${ }^{1}$, Yi-Chieh Yang ${ }^{1}$, Sze-Kwan Lin ${ }^{2}$, Peter Mu-Hsin Chang ${ }^{3,4^{*+}}$ and Michael Hsiao ${ }^{1,5^{*+}}$ (D)

\begin{abstract}
Background: Cisplatin is the first-line chemotherapy used against most upper aerodigestive tract carcinomas. In head and neck cancer, sensitivity to cisplatin remains the key issue in treatment response and outcome. Genetic heterogeneity and aberrant gene expression may be the intrinsic factors that cause primary cisplatin-resistance.

Methods: Combination of the HNSCC gene expression data and the cisplatin sensitivity results from public database. We found that aldo-keto reductase family 1 member C1 (AKR1C1) may be associated with cisplatin sensitivity in HNSCC treatment of naïve cells. We examined the AKR1C1 expression and its correlation with cisplatin $I_{50}$ and prognosis in patients. The in vitro and in vivo AKR1C1 functions in cisplatin-resistance through overexpression or knockdown assays, respectively. CDNA microarrays were used to identify the upstream regulators that modulate AKR1C1-induced signaling in HNSCC. Finally, we used the cigarette metabolites to promote AKR1C1 expression and ruxolitinib to overcome AKR1C1-induced cisplatin-resistance.

Results: AKR1C1 positively correlates to cisplatin-resistance in HNSCC cells. AKR1C1 is a poor prognostic factor for recurrence and death of HNSCC patients. Silencing of AKR1C1 not only reduced in vitro IC 50 but also increased in vivo cisplatin responses and vise versa in overexpression cells. Cigarette metabolites also promote AKR1C1 expression. Transcriptome analyses revealed that STAT1 and STAT3 activation enable AKR1C1-induced cisplatinresistance and can be overcome by ruxolitinib treatment.

Conclusions: AKR1C1 is a crucial regulator for cisplatin-resistance in HNSCC and also poor prognostic marker for patients. Targeting the AKR1C1-STAT axis may provide a new therapeutic strategy to treat patients who are refractory to cisplatin treatment.
\end{abstract}

Keywords: AKR1C1, Cisplatin-resistance, HNSCC, STATs, Ruxolitinib

\section{Introduction}

Cisplatin is the standard chemotherapeutic drug in head and neck squamous cell carcinoma (HNSCC) treatment [1] . Cisplatin causes platinum-DNA adducts that induce G2/S arrest and subsequent cell death in rapidly growing cancer cells. Furthermore, cisplatin also increases highly

\footnotetext{
* Correspondence: ptchang@vghtpe.gov.tw; mhsiao@gate.sinica.edu.tw

${ }^{\dagger}$ Peter Mu-Hsin Chang and Michael Hsiao are senior authors and contribute equally to this works.

${ }^{3}$ Department of Oncology, Taipei Veterans General Hospital, Taipei, Taiwan

${ }^{1}$ Genomics Research Center, Academia Sinica, Taipei, Taiwan

Full list of author information is available at the end of the article
}

reactive mono- and biaquated cisplatin forms [2] and intracellular reactive oxygen species (ROS) levels following reaction with cytoplasmic proteins and biomolecules [3]. For treatment of naïve, locally advanced HNSCC patients, the initial cisplatin-based chemotherapy response can be up to $50 \%$ [4]. Half of the patients remain without response to cisplatin; furthermore, most patients will develop acquired cisplatin-resistance, which induces cancer recurrence. Cisplatin-resistance and recurrence are the major factors leading to cisplatin-based therapeutic failure in HNSCC patients [5]. Thus, it is important to

(C) The Author(s). 2019 Open Access This article is distributed under the terms of the Creative Commons Attribution 4.0 International License (http://creativecommons.org/licenses/by/4.0/), which permits unrestricted use, distribution, and 
understand the mechanism of cisplatin-resistance, which may enable the development of strategies that help patients to overcome chemoresistance and improve clinical outcome in HNSCC.

A tumor is a heterogeneous cell mixture which harbors various genetic mutations and diverse gene expression. Therefore, precision medicine has become a rising field in cancer therapy [6]. Recently, patient-derived tumor xenograft models function as accurate preclinical models to predict therapeutic response; however, they are labor intensive and expensive projects for the prediction of therapeutic outcome [7]. In contrast, a well characterized cancer cell line database such as Genomics of Drug Sensitivity in Cancer (GDSC) [8-10] could provide reliable information on chemotherapy drug-response, and gene expression profiles from the Cancer Cell Line Encyclopedia (CCLE) [11] could provide guidance in the search for novel resistance genes. Moreover, the expression level of candidate genes and their prognostic value can be examined in public microarray databases or TCGA cohorts of clinical cancer patients [12-14]. Using in silico analysis could assist researchers in elucidating the candidate genes accounting and provide a potential therapy niches for overcoming chemoresistance in HNSCC.

The mammalian hydroxysteroid dehydrogenases comprise four enzymes (AKR1C1-C4) that catalyze reduction of steroids and prostaglandins [15] and cluster on the chromosome 10p14-15 region. AKR1C1 and C2 are located on different strands of DNA but have highly similar (> 98\%) protein coding sequences [16]. AKR1C1 and -C2 contribute $40 \%$ of the detoxification function of 4methylnitrosamino-1-(3-pyridyl)-1-butanone (NNK) in tobacco-derived nitrosamine carcinogens [17] In this study, we analyzed the HNSCC cell gene expression profiles and inhibitory concentration $\left(\mathrm{IC}_{50}\right)$ of cisplatin from the CCLE and GDSC databases. Interestingly, the AKR1C1 expression level was highly correlated to cisplatin $\mathrm{IC}_{50}$, and modulated AKR1C1 expression could affect the cisplatin response. Furthermore, the cigarette metabolites stimulate AKR1C1 expression in HNSCC. Using a JAK inhibitor will overcome AKR1C1 induced primary cisplatin-resistance. Here, we provided a novel, independent enzymatic mechanism of AKR1C1 through STAT3 activation for primary cisplatin-resistance in HNSCC.

\section{Materials and methods}

\section{In silico analysis of cisplatin response and patient} prognosis

The HNSCC gene expression profiles (GSE36133) in the CCLE database [11] were downloaded from Gene Expression Omnibus (GEO) and analyzed by Genespring GX software (Agilent). The HNSCC cisplatin $\mathrm{IC}_{50}$ data were downloaded from the GDSC database (release version 4, [10]). The TCGA HNSCC prognostic value and clinical characteristics of the recurrent HNSCC cohort were analyzed in SurvExpress or the CancerBrowser database and reformatted in GraphPad Prism or SPSS Software.

\section{Cell culture and reagents}

Cell cultures were prepared and maintained according to a standard protocol. $293 \mathrm{~T}, \mathrm{FaDu}, \mathrm{Cal}-27, \mathrm{HSC}-2$, and HSC-4 cells were purchased from ATCC or JCRB cell bank and maintained according to the manufacturer's instructions. Chemical reagents, vectors, and antibodies are listed in Additional file 1: Table S1. The cisplatin and 5-PBSA were prepared in sterile PBS or water and the ruxolitinib and cigarette metabolites, such as NAB, NAT, NNK and NNN, were prepared in DMSO.

\section{Cell viability assay and caspase activity assay}

In the cisplatin viability assay, HNSCC cells $\left(2 \times 10^{3}\right)$ were seeded in 96-well plates. After incubation overnight, the medium was replaced with $200 \mu \mathrm{l}$ fresh medium containing various dosages of cisplatin, 5-PBSA or ruxolitinib for $72 \mathrm{~h}$. At the endpoint, the medium was replaced with $200 \mu \mathrm{l}$ fresh medium containing $30 \mu \mathrm{l} \mathrm{Ala-}$ marBlue solution, then incubated an additional $4 \mathrm{~h}$ and measured for fluorescent intensity (Ex/Em: $560 \mathrm{~nm} / 590$ $\mathrm{nm})$. In the caspase activity assay, stable cells were infected by pCT-Apoptosis-Luc virus and seeded in 6-well plates $\left(2 \times 10^{5} /\right.$ well $)$. Then, cells were incubated in the same conditions as previously described, but the caspase activity was measured by the One-Glo ${ }^{\mathrm{Tm}}$ luciferase assay after cisplatin treatment at the $\mathrm{IC}_{50}$ for $24 \mathrm{~h}$.

\section{Vector construction, gene expression and microarray assay}

All primer sequences are listed in Additional file 1: Table S1. The AKR1C1 and AKR1C2 cDNA was purchased from DNASU and wild type and constitutive activation STAT1 and STAT3 were purchased from Addgene then recombined into pLenti6.3-DEST through gateway LR II recombinase. The enzymatic domain dead E127D clone was generated from AKR1C1 cDNA by site-direct mutagenesis. The AKR1C1 knockdown clones were purchased from RNAiCore (Taiwan). The AKR1C1 gene manipulation was performed as previously described [18]. AKR1C1 promoter region ( -1276 to +0$)$ was amplified from Cal-27 genomic DNA then cloned into $\mathrm{HE}$ cloning kit (Bio-tools, Taiwan) then confirmed sequence by Sanger sequencing. Then AKR1C1 promoter was subclone into SBI pGreenfire reporter vector. The AKR1C1 downstream genes and regulators in HNSCC were discovered by Affymetrix U133 microarray assays. The microarray analysis approach was analyzed as previously described [19]. Genes that were up- or downregulated 
with greater than 1.5-fold changes in response to AKR1C1 overexpression/knockdown were further subjected to computational simulation by Ingenuity Pathway Analysis (IPA; QIAGEN, Valencia, CA, USA) online tools to predict potential upstream regulators and the significant cellular pathways and functions. The microarray data were uploaded to the National Center for Biotechnology Information Gene Expression Omnibus (GEO, NCBI, GSE119444). The specific genes were validated by realtime CPR with EvaGreen-based qPCR assays.

\section{Western blot and real-time quantitative PCR (qPCR)}

Western blot analyses and qPCR conditions were performed as previously described [20]. The antibody dilution conditions and primer sequences are listed in Additional file 1: Table S1.

\section{Cancer stem cell sphere formation assay}

Stable cells $\left(1 \times 10^{3}\right)$ were seeded in Corning Ultralow attachment 6-well plates with $2 \mathrm{~mL}$ sphere medium (50 $\mathrm{mL}$ DMEM with $20 \mathrm{ng} / \mathrm{mL}$ EGF, bFGF and $1 \mathrm{~mL}$ B27 supplement) and then incubated for 14 days to form cancer spheroids. Spheroids were stained with Hoechst 33342, and the spheroid numbers were measured by an ImageXpress Micro XLS HCS system. The spheroid number was counted only when cell number was above 50 cells.

\section{Animal studies}

All animal experiments were performed in strict accordance with the recommendations in the guidelines for the Care and Use of Laboratory Animals of Academia Sinica. The protocol was approved by the Institutional Animal Care and Use Committee of the Genomic Research Center, Academia Sinica (Protocol No: AS-IACUC-18-03-1195). Male Nod-SCID gamma (NSG) mice aged 5-6 weeks were bred in the Genomic Research Center. The animals were housed in a climate-controlled room (12:12 dark-light cycle, with constant humidity and temperature) with food and water provided ad libitum. All efforts were made to minimize suffering. For the in vivo tumor burden assay, $5 \times 10^{6}$ stable cells were resuspended in sterile phosphate-buffered saline (PBS), then injected subcutaneously (SC) into the right flank of the mice. Each group consisted of 5 animals. The tumor burden was measured with the following formula: tumor volume $(\mathrm{V})=\mathrm{L} \times \mathrm{W} \times \mathrm{H}$. The mice were sacrificed, and the tumors were weighed and photographed. In in vivo cisplatin response assays, $2 \mathrm{mg} / \mathrm{kg}$ cisplatin were dissolved in PBS then injected through intraperitoneal injection.

\section{Statistical analysis}

The association between cisplatin response and HNSCC gene expression level was analyzed by Pearson correlation coefficient. The $\mathrm{HNSCC} \mathrm{IC}_{50}$ values were determined by the curve-fitting model with four-parameter logistic equation model in GraphPad Prism Software. An unpaired $\mathrm{t}$-test was performed to compare the mRNA expression levels in different treatment groups. Estimates of the survival rates were calculated using the Kaplan-Meier method and compared using the log-rank test. Patient follow-up time was censored if the patient was lost during follow-up. For all experiments, bar graphs represent the mean $( \pm S E M)$ from three independent experiments, and statistical analyses were performed using SPSS (Statistical Package for the Social Sciences) 21.0 software. Unless otherwise stated, significant differences between means were determined using a Student's $t$-test. A $p$ value of $<0.05$ was considered significant for all of our analyses.

\section{Results \\ AKR1C1 expression is correlated with cisplatin-resistance and clinical outcome}

To find the genes correlated to cisplatin response in HNSCC cells, we combined the CCLE gene expression profiles (Fig. 1a) and cisplatin $\mathrm{IC}_{50}$ results from GDSC (Fig. 1b). We used PermutMatrix [21] to analyze the hierarchical clustering of HNSCC gene expression profiles based on cisplatin $\mathrm{IC}_{50}$ from GDSC. Intriguingly, most HNSCC cells were clustered together, except Cal27 and HSC-4. AKR1C1 and AKR1C2 expression were downregulated in $\mathrm{Cal}-27$ and $\mathrm{HSC}-4$ cells. The multiple probes of AKR1C1/C2 which target to different sequence of $\mathrm{AKR} 1 \mathrm{C} 1 / \mathrm{C} 2 \mathrm{mRNA}$ and their consistency trends in the heat maps were correlated to cisplatin $\mathrm{IC}_{50}$. This observation indicated that AKR1C1/2 level might contribute to cisplatin response in HNSCC cells. However, the redundant enzymatic function and highly similar protein-coding sequences of AKR1C1 and AKR1C2 made them difficult to distinguish with commercial antibodies and functional assays. AKR1C1 and C2 may have the same gene regulation or cisplatinresistance mechanisms in HNSCC cells. Thus, we chose AKR1C1 as an example to examine its role in cisplatinresistance in HNSCC. We further analyzed the prognostic value and clinical characteristics information of AKR1C1 in HNSCC patients (Fig. 1c and Additional file 2: Table S2). High AKR1C1 expression level could be a poor prognostic marker in TCGA HNSCC cohort (hazard ratio, $\mathrm{HR}=1.84, p=0.035$ ). Patients with higher AKR1C1 expression demonstrated shorter median survival time (36.33 months) than those with lower AKR1C1 expression (66.73 months). AKR1C1 is correlated to HPV p16 expression, lymph node metastasis by hematoxylin and eosin 


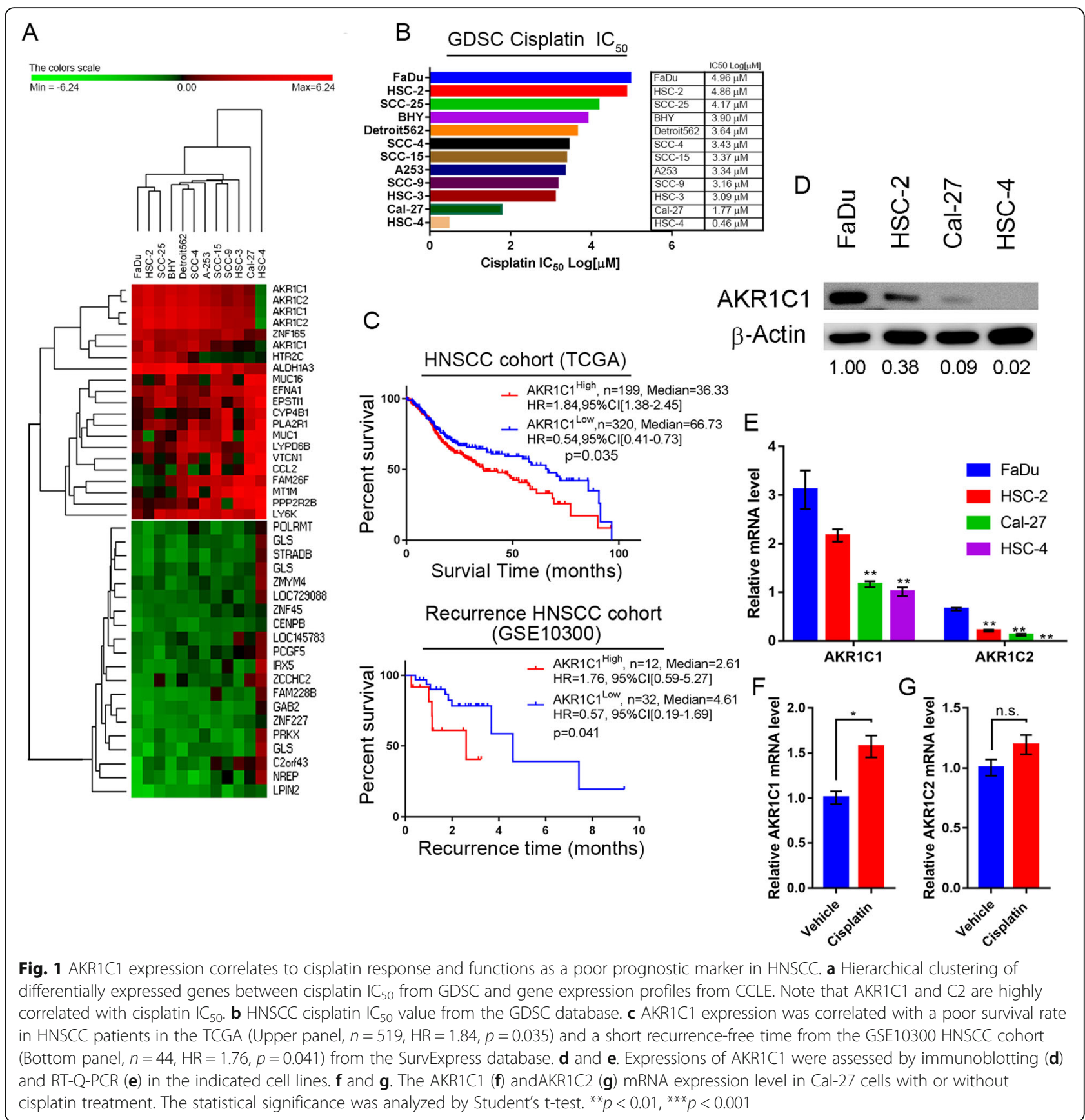

stain, SCC histologic grade and smoking history of the patient (Additional file 2: Table S2). Furthermore, in the recurrent HNSCC patient cohort (GSE10300), patients with higher AKR1C1 expression were prone to recur earlier (2.61 months) than those patients with lower AKR1C1 expression (4.61 months). We also examined the in vivo tumorigenesis ability (Additional file 3: Figure S1) and AKR1C1 expression level (Fig. 1d and e) in HNSCC cells. We found AKR1C1 was a more dominant form than AKR1C2 in HNSCC cells (Fig. 1e). Furthermore, we also found cisplatin treatment could significantly stimulate
AKR1C1 mRNA expression but not AKR1C2 mRNA (Fig. If and $\mathrm{g}$ ). Taken together, these results indicated that AKR1C1 expression could be a poor prognostic and recurrent biomarker in HNSCC patients.

\section{Silencing of AKR1C1 can increase cisplatin response in HNSCC through enzyme independent function}

To understand the AKR1C1 function in HNSCC related cisplatin-resistance, we performed AKR1C1 shRNA silencing in high AKR1C1 expressing cells, $\mathrm{FaDu}$ and HSC-2 (Fig. 2a and d). The shRNA clone that was 
A $\frac{\left.\text { FaDu (AKR1C1 }{ }^{\text {High }}\right)}{\text { shLuc }} \begin{aligned} \text { shAKR1C1 } \\ \text {-CDS -UTR }\end{aligned}$

AKR1C1

$\beta$-ACTIN
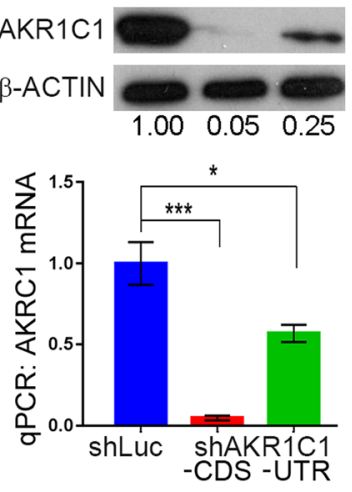

D HSC-2 (AKR1C1 ${ }^{\text {High) }}$

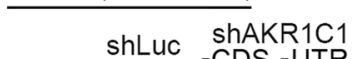

AKR1C

B-ACTIN

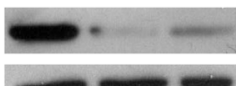

$\begin{array}{lll}1.00 & 0.13 & 0.21\end{array}$

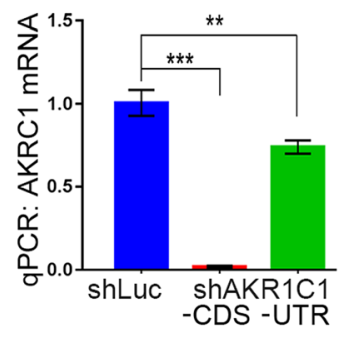

$\mathrm{B} \frac{\partial}{2}$

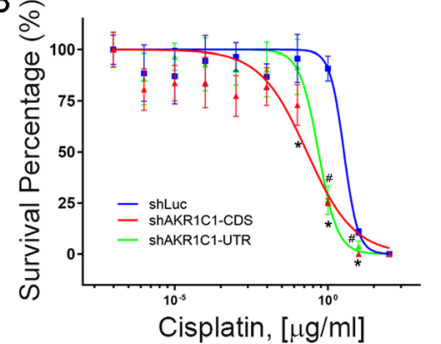

C with [cisplatin, $I_{50}$ ]

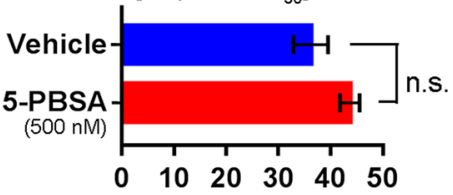

Survival Percentage (\%)

E

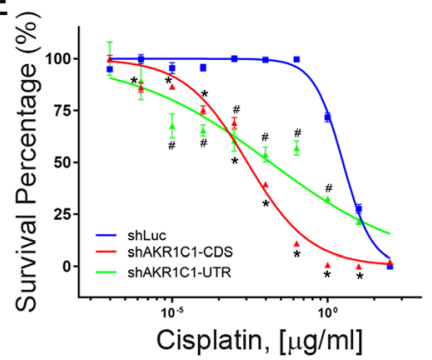

$\mathrm{F}$ with [cisplatin, $I \mathrm{C}_{50}$ ]

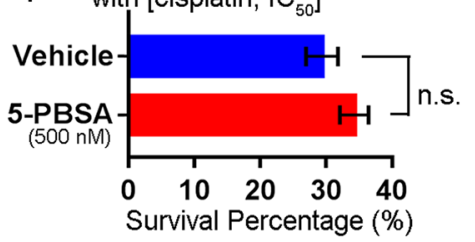

G HSC-2 (AKR1C1 ${ }^{\text {High }}$

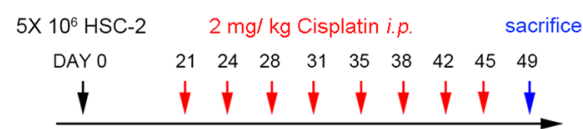

$\mathrm{H}$

DAY
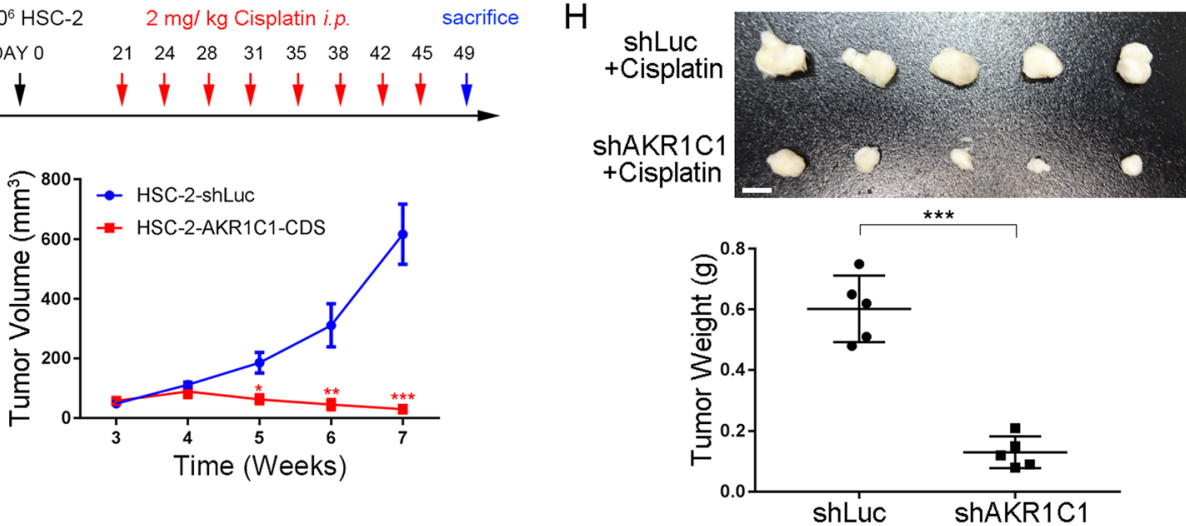

Fig. 2 Silencing of AKR1C1 can increase the cisplatin response activity in HNSCC cells through enzyme-independent functioning. $\mathbf{a}$ to $\mathbf{f}$ The in vitro cell viability assay after combining cisplatin and shAKRIC1 lentiviral particles or enzymatic AKR1C1 inhibitor, 5-PBSA, in highly AKRIC1 expressed cells. a and $\mathbf{d}$ AKR1C1 protein (upper) and mRNA (bottom) expression after knockdown of AKR1C1. $\mathbf{b}$ and $\mathbf{e}$ Dose-response curve after knockdown of AKR1C1. $\mathbf{c}$ and $\mathbf{f}$ The cell viability assay under cisplatin $I_{50}$ and with or without AKR1C1 inhibitor, 5-PBSA $(500 \mathrm{nM}) . \mathbf{g}$ and $\mathbf{h}$ The HSC-2 in vivo cisplatin response assay in which cells were infected with or without AKR1C1-CDS knockdown clones. $\mathbf{g}$ The cisplatin regimen (upper) and in vivo tumor burden (bottom, $n=5$ ). The cisplatin was given $2 \mathrm{mg} / \mathrm{kg}$ through intraperitoneal injection (i.p.).h The tumor image and tumor weights from (g) and the scale bar indicates $0.5 \mathrm{~cm}$ length. The statistical significance was analyzed by Student's t-test. ${ }^{* *} p<0.01,{ }^{* *} p<0.001$ 
targeted to the protein coding sequence (CDS) revealed higher efficacy than the clone targeted to the untranslated region (UTR). We used the curve-fitting model to indicate cisplatin response in $\mathrm{FaDu}$ and HSC-2 cells where the AKR1C1 expression was silenced by shAKR1C1 pseudoviruses. The $\mathrm{IC}_{50}$ values of the shAKR1C1 RNAs in $\mathrm{FaDu}$ cells when targeted to CDS were $686.55 \mathrm{nM}$ with 95\% CI $=382.27$ to $1232.79 \mathrm{nM}$; when targeted to UTR were $1635.39 \mathrm{nM}$ with $95 \% \mathrm{CI}=1182.13$ to $2262.28 \mathrm{nM}$; and for the control shLuc were $11,061.45 \mathrm{nM}$ with $95 \%$ $\mathrm{CI}=7572.04$ to $16,153.92 \mathrm{nM}$. In addition, the $\mathrm{IC}_{50}$ values of the shAKR1C1 RNAs in HSC-2 cells when targeted to CDS $\mathrm{IC}_{50}$ were $8.70 \mathrm{nM}$ with $95 \% \mathrm{CI}=6.33$ to $11.96 \mathrm{nM}$; when targeted to UTR were $47.53 \mathrm{nM}$ with $95 \% \mathrm{CI}=$ 16.86 to $133.91 \mathrm{nM}$; and for the control shLuc were 10 , $294.92 \mathrm{nM}$ with $95 \% \mathrm{CI}=8808.50$ to $12,031.29 \mathrm{nM}$, (Fig. $2 \mathrm{~b}$ and e). The AKR1C1 expression level showed a comparable response of cisplatin toxicity in $\mathrm{FaDu}$ and $\mathrm{HSC}-2$ cells. When $\mathrm{FaDu}$ and HSC-2 cells were cotreated with cisplatin with or without the AKR1C1 inhibitor, 5-PBSA [22], the cell viability was unchanged in both cells (Fig. 2c and f). These results indicated that the cisplatin-resistance function may not depend on AKR1C1 enzyme function. We further validated that in vivo AKR1C1 induced cisplatin-resistance in NSG mice (Fig. 2g). Reducing AKR1C1 expression in HSC-2 shAKR1C1 silenced cells could increase the cisplatin response effect compared with the shLuc control cells (Fig. 2h). These results indicated that AKR1C1 can promote cisplatin-resistance in an enzyme-independent manner.

\section{Ectopic AKR1C1 can promote cisplatin-resistance, anti- apoptosis response and cancer stemness in HNSCC}

To further investigate the role of AKR1C1 in cisplatinresistance, we used the two-way model to analyze AKR1C1 functions in cells expressing lower, endogenous levels of AKR1C1, HSC-4 and Cal-27 (Fig. 3a and c). Ectopic AKR1C1 expression could increase the cisplatin $\mathrm{IC}_{50}$ from $11.28 \mathrm{nM}$ (Fig. 3b, HSC-4, 95\% CI $=7.085$ to $17.96 \mathrm{nM}$ ) to $833.19 \mathrm{nM}$ ( $95 \% \mathrm{CI}=685.55$ to 1012.83 $\mathrm{nM}$ ), and $14.34 \mathrm{nM}$ (Fig. 3d, Cal-27, 95\% CI $=10.72$ to $19.20 \mathrm{nM})$ to $5805.68 \mathrm{nM}(95 \% \mathrm{CI}=10,717.18$ to 19 , $196.73 \mathrm{nM}$ ), respectively. Cal-27 cells demonstrated higher in vivo tumorigenesis ability in NSG mice than HSC-4 cells (Additional file 3: Figure S1); thus, we chose Cal-27 for further in vivo cisplatin response assays in NSG mice and in vitro mechanism assays of cisplatinresistance. Compared to empty vector control (VC), AKR1C1 expression could decrease the cytotoxicity effects in Cal-27 cells (Fig. 3e and f). Furthermore, AKR1C1 expression could reduce the caspase activity in cisplatin-treated Cal-27 cells (Fig. 3g). Cancer stem cells play a major role in drug resistance and tumor recurrence and $\mathrm{AKR} 1 \mathrm{C} 1 / \mathrm{C} 2$ are upregulated in a minor population of lung cancer stem cells [23]. We further examined the cancer sphere formation ability of AKR1C1, which could increase the cancer spheroids in Cal-27 cells (Fig. 3h). In order to prove that AKR1C1 induced cisplatin-resistance through enzymatic-independent manner, we used domain negative AKR1C1-E127D clone and found that both wild type AKR1C1 and AKR1C1-E127D clone could induce cisplatin resistance in Cal-27 (Fig. 4a to d). These results indicated that AKR1C1 expression could increase cisplatin-resistance in HNSCC.

\section{AKR1C1 induces STAT activation and influences downstream survival and inflammatory signaling in HNSCC}

To ascertain the mechanism by which AKR1C1 induced cisplatin-resistance in HNSCC, we performed microarray analysis in a two-way model of AKR1C1 overexpression and knockdown in Cal-27 and HSC-2 cells (Fig. 5a). The normalized data from the microarray analysis were subjected to IPA to identify the crosstalk of the AKR1C1 signaling network in HNSCC (Additional file 4: Table S3 and Additional file 5: Table S4). AKR1C1 expression activated several oncogenic functions including tumor cell viability, metastasis, and angiogenesis. Several tumor suppression pathways including apoptosis and necrosis were suppressed by AKR1C1 expression (Fig. 5b and Additional file 4: Table S3). Taken together, these results suggest that AKR1C1 might contribute to tumor progression and prevent tumor cell death in HNSCC. Moreover, we also analyzed the dynamics of cellular regulators upon AKR1C1 expression, finding that the downstream genes belonging to TNF and TGFB1 were controlled by AKR1C1. (Fig. 4c and Additional file 5: Table S4). Interestingly, both downstream regulators belonged to inflammatory genes and were also controlled by oncogenic signaling proteins, signal transducer and activator of transcription (STAT) families, in different cell types. Recently, Zhu et al. reported an AKR1C1 enzymatic-independent function in STAT3 activation in lung cancer cells [24]. Thus, we used the STAT family luciferase reporters to examine the STAT activity under AKR1C1 expression. In Cal-27 cells, AKR1C1 expression promoted STAT1 and STAT3 transcriptional activity and stimulated protein phosphorylation in transcriptional activation and dimerization tyrosine residues Y705 and Y701 in STAT3 and STAT1, respectively (Fig. $5 \mathrm{~d}$ and e). STAT1 and STAT3 had direct interaction with AKR1C1 in HSC-2 cells which had high cisplatin $\mathrm{IC}_{50}$ and AKR1C1 expression (Fig. 5f). Moreover, the constitutive activation STAT1-Y701F and STAT3-STAT3 could promote cisplatin-resistance in Cal-27 cells (Fig. 5e and f). The tyrosine phosphorylation of STAT1 and STAT3 are catalyzed by Janus kinase (JAK) and control the STAT1 and 3 downstream transcriptome, including the TGF-B1 and TNF gene network, and promote tumor progression 


\section{A $\mathrm{HSC}-4$ (AKR1C1 1Lw)}

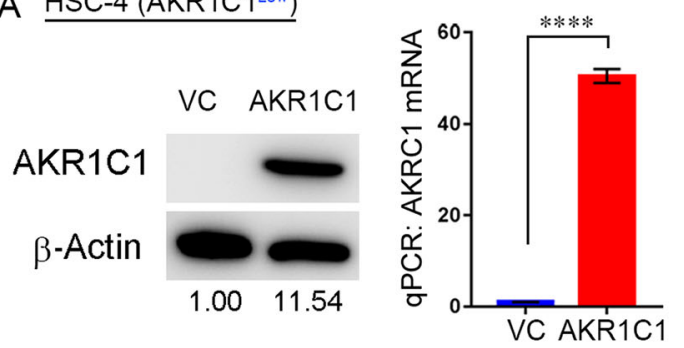

C Cal-27 (AKR1C1 1'

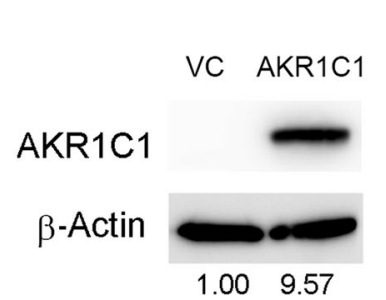

E

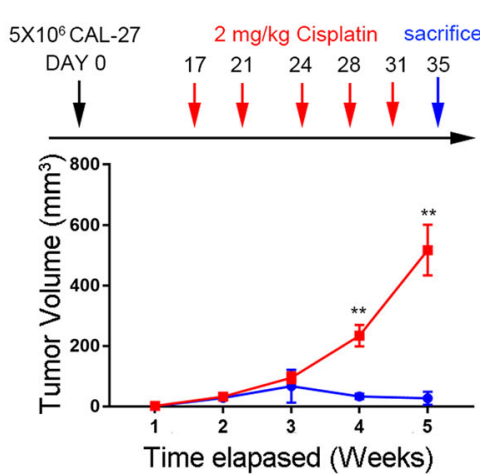

G

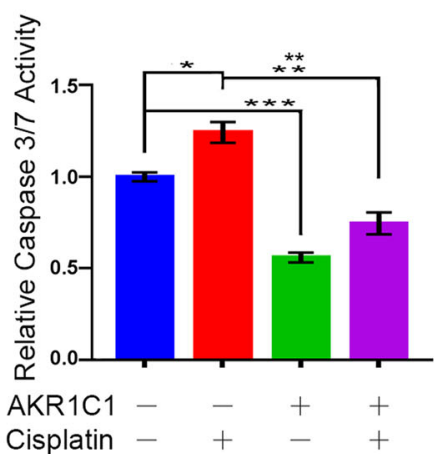

$\mathrm{F}$

$\mathrm{H}$
B

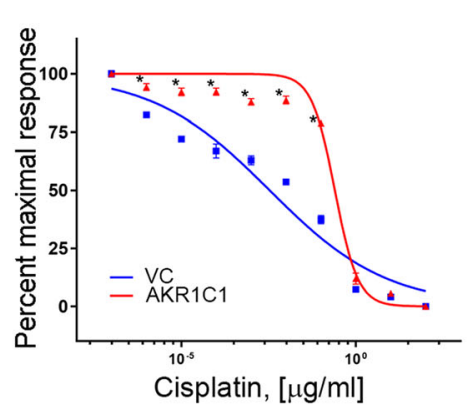

D

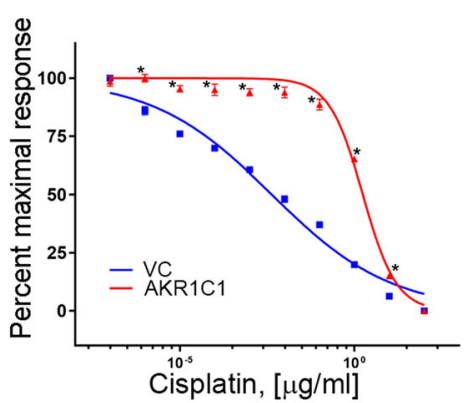

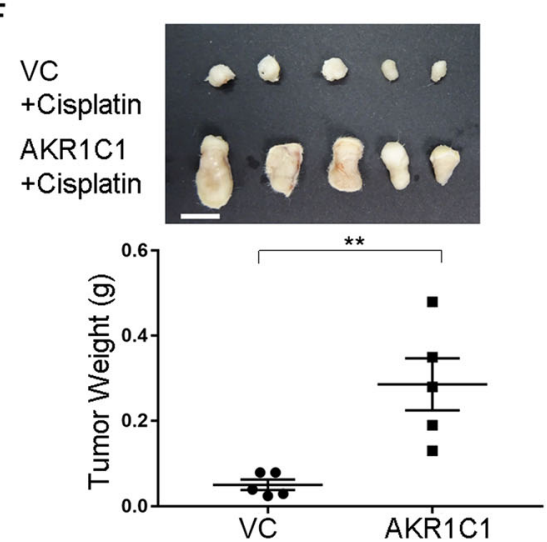
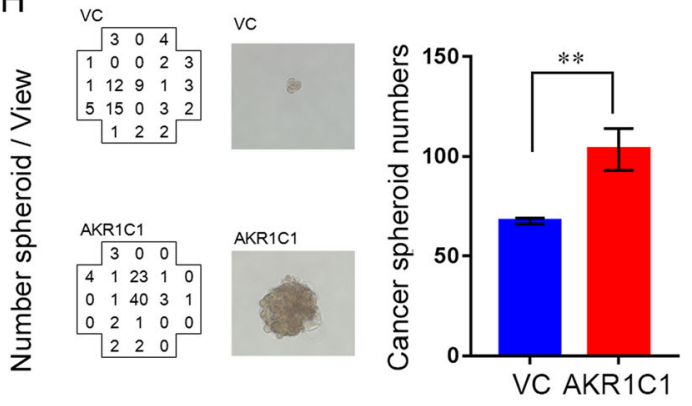

Fig. 3 Ectopic AKR1C1 can promote cisplatin-resistance, anti-apoptosis response and cancer stemness in HNSCC cells. a to $\mathbf{d}$ The in vitro cell viability assay after combining cisplatin and ectopic AKR1C1 lentiviral particles. a and c AKR1C1 protein (left) and mRNA (right) expression after enforced expression of AKR1C1. $\mathbf{b}$ and $\mathbf{d}$ Dose-response curve after enforced expression of AKR1C1. e and $\mathbf{f}$ The Cal-27 in vivo cisplatin response assay in which cells were infected with or without AKR1C1 overexpression clones. e The cisplatin regimen (upper) and in vivo tumor burden (bottom, $n=5$ ). The cisplatin was given $2 \mathrm{mg} / \mathrm{kg}$ through intraperitoneal injection (i.p.). $\mathbf{f}$ The tumor image and tumor weights from (e) and the scale bar indicates $1 \mathrm{~cm}$ length. $\mathbf{g}$ The cisplatin-induced caspase 3/7 activity assay with or without AKR1C1 expression. $\mathbf{h}$ The cancer spheroid formation assays with or without AKR1C1 expression in Cal-27 cells. The left panels indicate spheroid numbers which were calculated by ImageXpress XLS High-content system and the middle panels indicate the representative spheroid image in high magnification. The statistical significance was analyzed by Student's t-test. ${ }^{* *} p<0.01,{ }^{* * *} p<0.001$ 

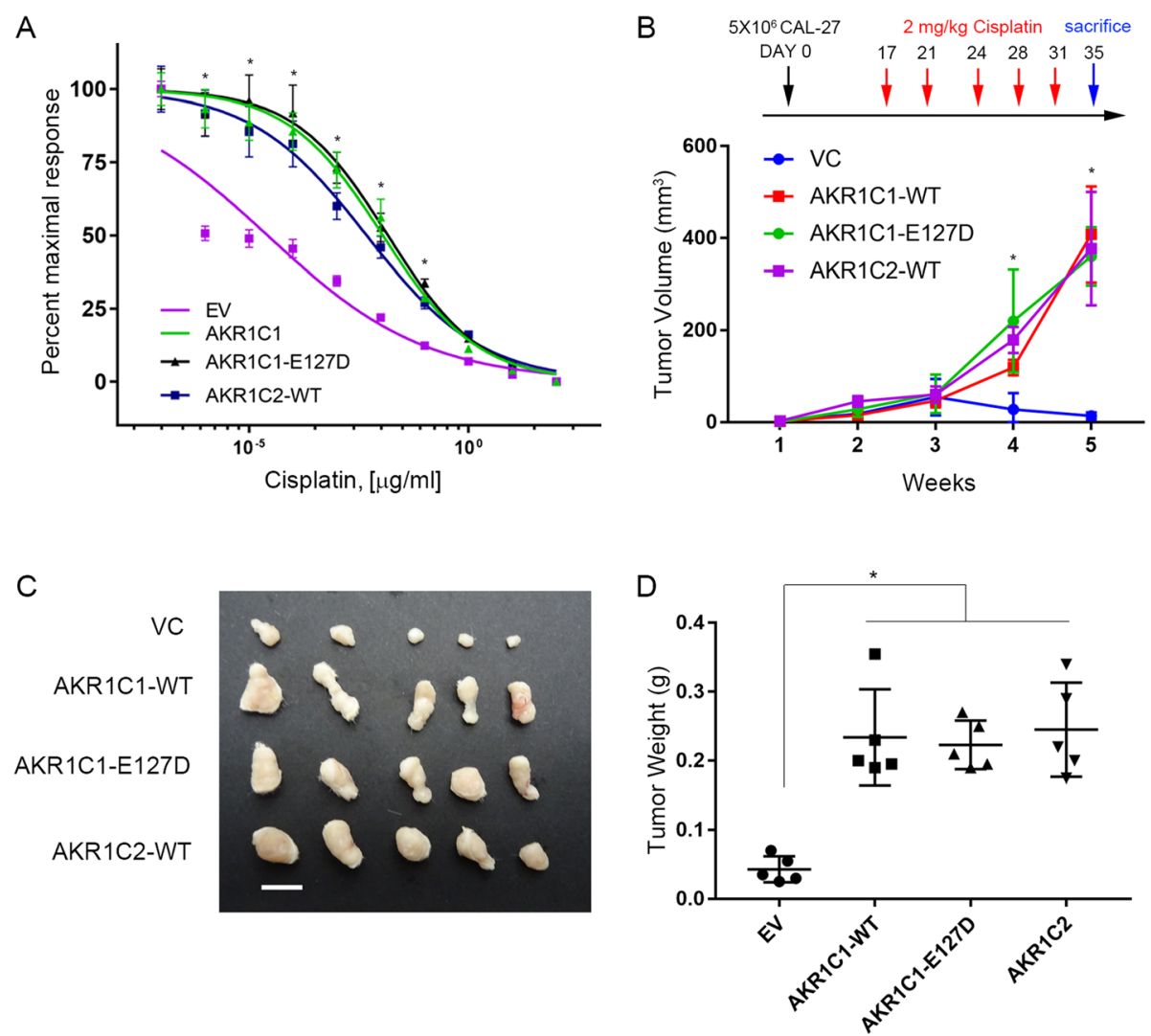

Fig. 4 AKR1C1 promotes cisplatin-resistance enzymatic-independent manner. a Cisplatin dose-response curve in wild type AKR1C1, AKR1C2, and domain-negative AKR1C1-E127D Cal-27 cells. b to d. b The cisplatin regimen (upper) and in vivo tumor burden (bottom, $n=5$ ). The cisplatin was given $2 \mathrm{mg} / \mathrm{kg}$ through intraperitoneal injection (i.p.). $\mathbf{c}$ and $\mathbf{d}$. The tumor image and tumor weights (d) from (c) and the scale bar indicates $1 \mathrm{~cm}$ length

and chemoresistance in cancer cells $[25,26]$. In HNSCC cells, we used real-time quantitative PCR to validation the microarray and IPA analysis upon AKR1C1. AKR1C1 controlled TGFB1, TNF gene expressions and several downstream genes including IL1R2, L1CAM, ROR1 and SPOCK1 in HNSCC cells (Fig. $5 \mathrm{i}$ to $\mathrm{k}$ ). These results indicated that AKR1C1 promotes the oncogenic signaling STAT1 and STAT3 activation and downstream signaling that might contribute to cisplatin-resistance in HNSCC.

\section{Cigarette metabolites promote AKR1C1 expression and STAT1 and 3 activation in HNSCC}

AKR1C1 is highly correlated to patient smoking history (Additional file 2: Table S2) and is also the most important detoxification enzyme of NNK (17). NNK and other tobacco-specific nitrosamines (TSNA), including NAB, NAT and NNN, are major carcinogens in cigarette smoking, which directly exposes the oral cavity and airway. In NSCLC cells, NNK treatment stimulates proliferation and inhibits chemotherapy-induced apoptosis through AKT and NF-kB activation [27, 28]. Thus, we examined whether exposure to TSNAs induces AKR1C1 and downstream gene expression in HNSCC cells. All TSNA exposure stimulated AKR1C1 promoter activity and AKR1C1 protein and mRNA expression in Cal-27 cells (Fig. 6 a-c). Using microarray analysis, we found TSNAs treatment could active the STAT3 signature in Cal-27 cells (Additional file 6: Table S5). Thus, we examined the phosphorylation statuses of STAT1 and 3 and their downstream gene expressions under TSNAs exposure (Fig. $6 \mathrm{~d} \&$ e). Furthermore, NNK and NNN could abolish the cisplatin toxicity in AKR1C1 knockdown cells (Fig. 6f). NNK and NNN had stronger effects than NAB and NAT in AKR1C1 induction and STAT signaling activation in Cal-27 cells. These results suggest that overexpression of AKR1C1 in HNSCC may be induced by cigarette smoking.

JAK inhibitor, ruxolitinib, prevents AKR1C1 induced JAKSTAT signaling and cisplatin-resistance

Ruxolitinib is a FDA-approved oral JAK inhibitor which has been used to treat patients with myeloproliferative disorders or polycythemia vera $[29,30]$. Ruxolitinib is also used to treat immunodysregulation in patients with 


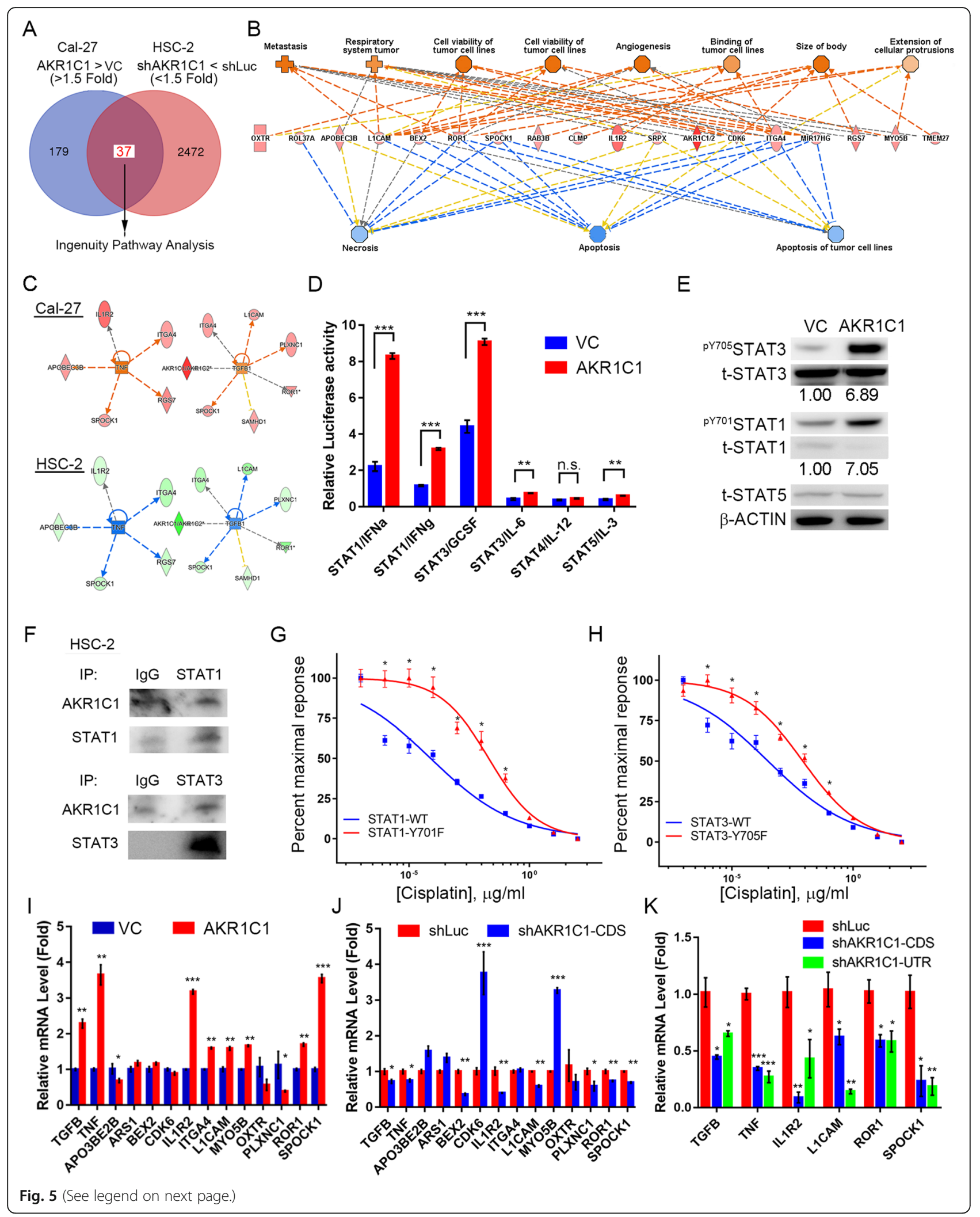


(See figure on previous page.)

Fig. 5 AKR1C1 controls anti-cell death pathways and inflammatory gene networks in HNSCC cells. a The flowchart of identifying the AKR1C1 downstream genes with 1.5-fold change cutoff compared to control vectors and their possible regulators in HNSCC cells. b The disease and biological function results from the IPA database c AKR1C1 regulates inflammation proteins, such as TNF-a and TGF- $\beta$ networks, by IPA in HSC-2 (d) and Cal-27 (e) cells. D. STAT family reporter activity assays. The reporter activity was normalized by the expression level of pGL4-miniP reporters in the stable cell lines. $\mathbf{e}$

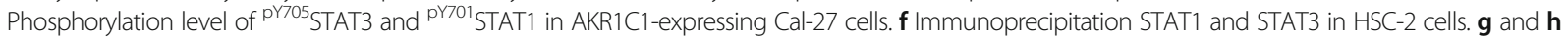
Cisplatin dose-response curve in Cal-27 expression with wild type STAT1 or constitutive activation form STAT1-Y701F (g) or STAT3 or STAT3-Y705F. I to $\mathbf{k}$. The real-time PCR validation of microarray candidates in AKR1C1 overexpression (I, Cal-27) and knockdown (J, HSC-2; K, FaDu) cells. The gene expressions were normalized with endogenous GAPDH expression. The statistical significance was analyzed by Student's t-test. ${ }^{*} p<0.05{ }^{* *} p<0.01,{ }^{* * *} p<0.001$

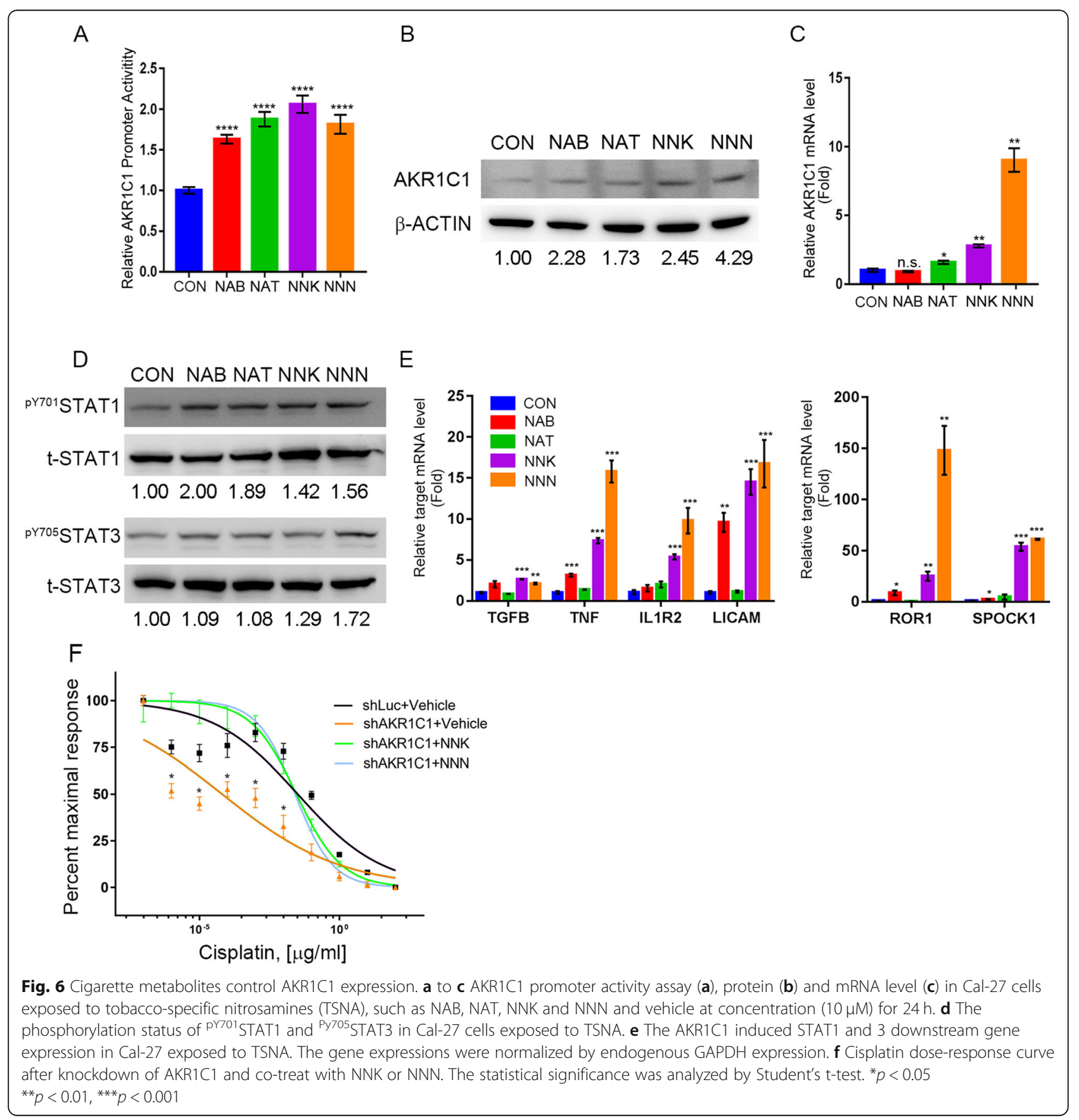


gain of function STAT1 or STAT3 mutations [31]. Recently, ruxolitinib has been tested in many clinical trials in different cancer types, including a phase 2 trial in head and neck cancer [32]. Thus, we examined the cisplatin sensitivity role of ruxolitinib in overcoming AKR1C1-induced cisplatin-resistance. In Cal-27 cells, ruxolitinib treatment could prevent $\mathrm{STAT}^{\mathrm{Y} 701}$ and STAT3 $^{\text {-Y705 }}$ phosphorylation, both of which were contributed by AKR1C1 (Fig. 7a). Combining ruxolitinib and cisplatin increased the apoptotic cell ratio in both Cal-27-AKR1C1 cells (Fig. 7b) and HSC-2 cells (Fig. 7c). Moreover, the expression level of AKR1C1-induced STAT1 and 3 target genes were also suppressed by ruxolitinib treatment in both cell types (Fig. 7d and e). Taken together, the results indicate that ruxolitinib might contribute to overcoming cisplatin-resistance in HNSCC.

\section{Discussion}

In this study, we determined that AKR1C1 may account for cisplatin-resistance via activating STAT signaling pathways, ultimately resulting in poor clinical outcome. Cisplatin has been the standard chemotherapy for most upper aerodigestive tract carcinomas, including HNSCC, lung cancer, and esophageal cancer, for decades. Mechanisms of cisplatin-resistance have also been discussed, and currently there are several major factors that are considered to contribute to it: membrane transporters for cisplatin uptake or efflux, such as CRT1 and ABC transporter MRP2; DNA repair proteins, such as ERCC1 and TP53; apoptosis associated proteins including BCL-2, caspases, or MAPKs [5]. Since primary cisplatin-resistance has been regarded as a very poor prognostic factor and many clinical trials have excluded patients who recurred within 6 months after primary or adjuvant cisplatin-based chemoradiotherapy in HNSCC, understanding additional details in cisplatin-resistance mechanisms can enable clinical oncologists and medical researchers to design novel therapeutic strategies for these cancer patients.

AKR1C1 expression is a poor prognostic marker in a wide variety of cancers, including breast, prostate, non-small cell lung, and esophagus [33], and it is upregulated in recurrent tumors and cancer stem cells $[23,33]$. In acquired cisplatin-resistance and metastatic ovarian and gastric cancer cells, AKR1C1 is upregulated by IL-6 stimulation and nuclear factor erythroid 2-related factor 2 (Nrf2) and promotes chemoresistance. [34-38]. Because AKR1C1 works as cellular ROS scavenger and up-regulation in cancer-stem cells which hint that AKR1C1 might be a broad-range chemoresistance gene in cancer. However, the molecular mechanism remains unclear of AKR1C1 in HNSCC cisplatin-resistant. In this study, we found
AKR1C1 contributing to cisplatin-resistance and cancer stemness phenotype in HNSCC. Furthermore, we found that cigarette metabolites could induce AKR1C1 expression and further activate STAT signaling. Previously, we identified an AKR1C1 enzymaticindependent mechanism that induced STAT1 and STAT3 activation in treatment-naïve NSCLC cells [24] and demonstrated that this activation could be attenuated by ruxolitinib. STATs are key regulators which stimulate IL-6 expression. AKR1C1, STATs, and cytokine IL-6 potentially form a positive feedback loop in cancer to enhance cisplatin-resistance.

Smoking is one of the most important environmental carcinogens that induces "field cancerization" in upper aerodigestive tract carcinoma [39]. There are more than 20 carcinogens involved in tobacco [40], and the smaller particles, such as air pollutants from second-hand smoke, may predominantly deposit in lung parenchyma and promote local inflammation. TSNAs, specifically NNK, promote NSCLC proliferation and prevent chemotherapy-induced apoptosis (32, 33); however, studies to provide similar information for HNSCC are relatively few. In this study, we determined that the similar chemical structure of NNK and NNN lead to more potent STAT-stimulating activity than NAB and NAT. These phenomena may arise from the inhibitory function of NNK in E3ligase protein and $\beta \operatorname{TrCP}[41]$ and prevent degradation of EMI1 and CTNNB1 [42] . The situation found in the oral cavity and upper aerodigestive tract may also occur in the lung. From this study we observed that AKR1C1 was overexpressed after exposure to TSNAs, resulting in STAT activation and cisplatinresistance (Fig. 7f). The reason why TSNAs would induce AKR1C1 expression may be due to the compensatory metabolic effects of the cells. Based on this evidence, upper aerodigestive tract carcinoma patients who are receiving cisplatin treatment should cease smoking immediately to prevent acquired cisplatinresistance.

Ruxolitinib is a JAK1/2 inhibitor that targets STATassociated signaling. It has been approved by the FDA for hematologic premalignancy including myelofibrosis and polycythemia vera. Clinical studies of ruxolitinib primarily focus on hematologic malignancies and some aggressive solid cancers that may harbor stem-like features, such as glioblastoma multiforme or triple negative breast cancer. In HNSCC, STAT3 activation has been observed in tumors and may be regulated by upstream EGFR overexpression, IL-6 inflammatory cytokines, or additional pathways. Targeting STAT3 to overcome drug resistance in HNSCC has been discussed, but trials are seldom conducted using ruxolitinib [43]. In this study, we showed that ruxolitinib could overcome 


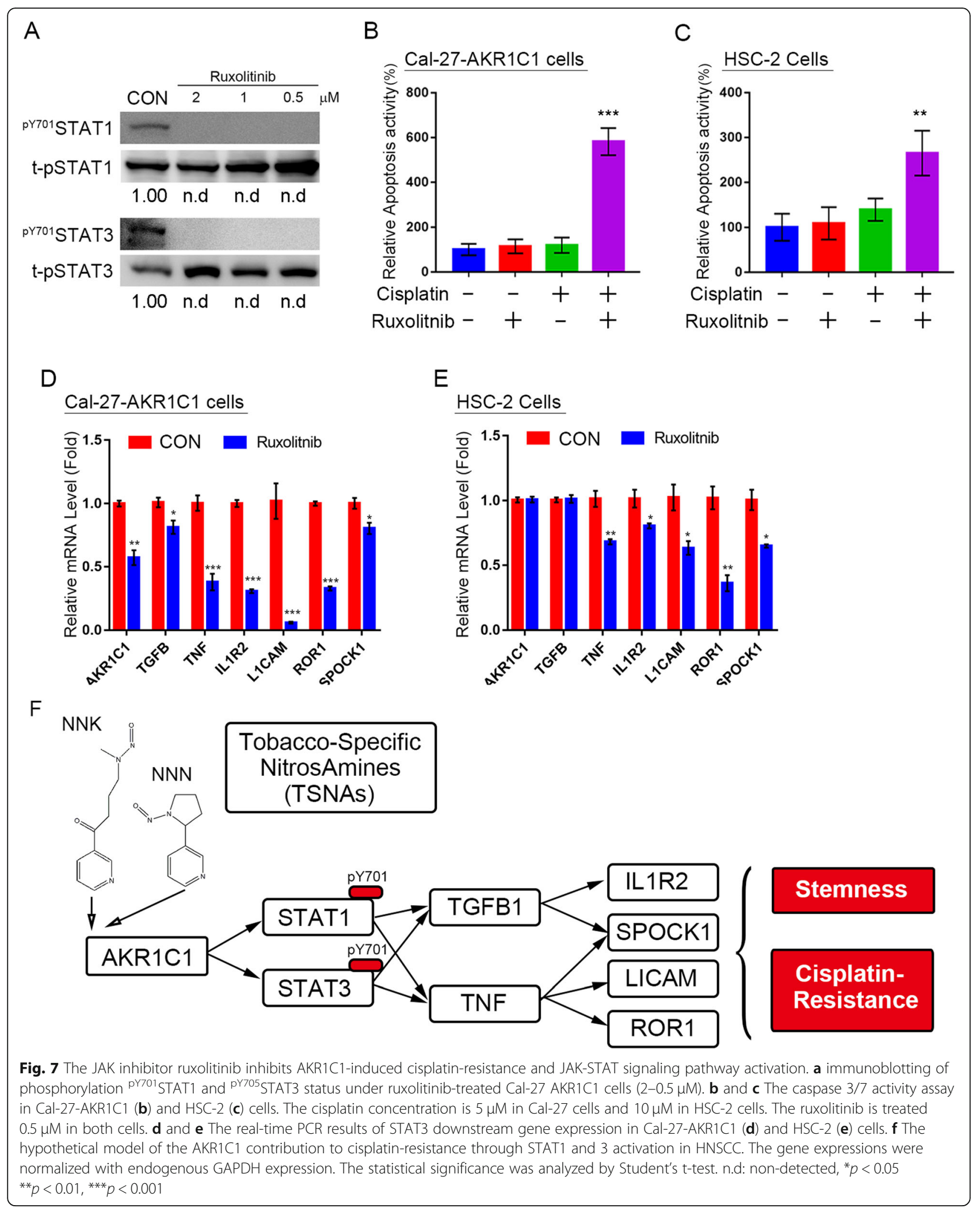

intrinsic cisplatin-resistance in HNSCC. Further studies focusing on targeting this novel AKR1C1/STAT network are warranted.

\section{Conclusions}

This is the first conceptual link between cigarette metabolites which induce AKR1C1 overexpression and 
cisplatin resistance in HNSCC and cause poor prognosis. The AKR1C1/STAT crosstalk is associated with primary cisplatin-resistance and may be overcome by the JAK inhibitor ruxolitinib. Whether AKR1C1 could be an effective prognostic or predictive factor for HNSCC patients treated with cisplatin-based chemotherapy warrants further validation. New combination therapy with cisplatin and drugs targeting AKR1C1/STAT signaling also may be beneficial to primary cisplatin-resistant HNSCC patients.

\section{Additional files}

Additional file 1: Table S1. Reagents and primer information in this manuscript (DOCX 23 kb)

Additional file 2: Table S2. Clinical Characteristics of AKR1C1 in TCGA HNSCC cohorts (DOCX 24 kb)

Additional file 3: Figure S1. In vivo tumor growth abilities in HNSCC cells. Figure S2. Full length Western blot images. (DOCX 2354 kb)

Additional file 4 Table S3. AKR1C1 controls cellular functions from Ingenuity Pathway Analysis (DOCX 17 kb)

Additional file 5 Table S4. AKR1C1 regulates Up-stream Regulators from Ingenuity Pathway Analysis (DOCX 16 kb)

Additional file 6 Table S5. The Up-stream Regulators of TSNAs treatment in Cal-27 cells from Ingenuity Pathway Analysis (DOCX 20 kb)

\section{Abbreviations}

GEO: Gene Expression Omnibus; HNSCC: Head and neck squamous cell carcinoma; NAB: N'-nitrosoanabasine; NAT: N'-nitrosoanatabine; NNK: 4(methylnitrosamino)1-(3-pyridyl)-1-butanone; NNN: N-nitrosonornicotine; NSG: Nod-SCID gamma; TSNAs: Tobacco-specific nitrosamines

\section{Publisher's Note}

Springer Nature remains neutral with regard to jurisdictional claims in published maps and institutional affiliations.

\section{Acknowledgements}

The authors would like to acknowledge the great help and assistance of Experimental Animal Imaging and Molecular Pathology Core Facilities of Genomic Research Center, Academia Sinica (Taipei, Taiwan).

\section{Authors' contributions}

Conception and design: MH, PMC, WMC. Development of methodology: WMC, YCC, YCY. Acquisition of data (provided animals, acquired and managed patients, provided facilities, etc.): WMC, Analysis and interpretation of data (e.g., statistical analysis, biostatistics, computational analysis): $\mathrm{MH}$, PMC, SKL, WMC, YCC, YC Y. Writing, review, and/or revision of the manuscript: $\mathrm{MH}, \mathrm{PM}$ C, WMC, YCC, YCY Administrative, technical, or material support (i.e., reporting or organizing data, constructing databases): MH. Study supervision: $\mathrm{MH}$. All authors read and approved the final manuscript.

\section{Funding}

The study was financially supported by the Academia Sinica [AS-SUMMIT108]] to Michael Hsiao and MOST 107-2627-M-075 -001 to Peter Mu-Hsin Chang.

\section{Availability of data and materials}

The microarray data were uploaded to the National Center for Biotechnology Information Gene Expression Omnibus (GEO, NCBI, GSE119444). Chemical reagents, vectors, and antibodies are listed in Additional file 1: Table S1.

\section{Ethics approval and consent to participate}

Not applicable

\section{Consent for publication}

Not applicable

\section{Competing interests}

The authors declare that they have no competing interests.

\section{Author details}

${ }^{1}$ Genomics Research Center, Academia Sinica, Taipei, Taiwan. ${ }^{2}$ Department of Dentistry, National Taiwan University Hospital, Taipei, Taiwan. ${ }^{3}$ Department of Oncology, Taipei Veterans General Hospital, Taipei, Taiwan. ${ }^{4}$ Faculty of Medicine, College of Medicine, National Yang-Ming University, Taipei, Taiwan. ${ }^{5}$ Department of Biochemistry, Kaohsiung Medical University, Kaohsiung, Taiwan.

Received: 31 January 2019 Accepted: 30 May 2019

Published online: 10 June 2019

\section{References}

1. Shen DW, Pouliot LM, Hall MD, Gottesman MM. Cisplatin resistance: a cellular self-defense mechanism resulting from multiple epigenetic and genetic changes. Pharmacol Rev. 2012;64:706-21.

2. Michalke B. Platinum speciation used for elucidating activation or inhibition of Pt-containing anti-cancer drugs. J Trace Elem Med Biol. 2010;24:69-77.

3. Dasari S, Tchounwou PB. Cisplatin in cancer therapy: molecular mechanisms of action. Eur J Pharmacol. 2014;740:364-78.

4. Urba SG, Moon J, Giri PG, Adelstein DJ, Hanna E, Yoo GH, Leblanc M, Ensley JF, Schuller DE. Organ preservation for advanced resectable cancer of the base of tongue and hypopharynx: a southwest oncology group trial. J Clin Oncol. 2005;23:88-95.

5. Galluzzi L, Senovilla L, Vitale I, Michels J, Martins I, Kepp O, Castedo M, Kroemer G. Molecular mechanisms of cisplatin resistance. Oncogene. 2012; 31:1869-83.

6. Dagogo-Jack I, Shaw AT. Tumour heterogeneity and resistance to cancer therapies. Nat Rev Clin Oncol. 2018;15:81-94.

7. Tentler JJ, Tan AC, Weekes CD, Jimeno A, Leong S, Pitts TM, Arcaroli JJ, Messersmith WA, Eckhardt SG. Patient-derived tumour xenografts as models for oncology drug development. Nat Rev Clin Oncol. 2012;9:338-50.

8. Haverty PM, Lin E, Tan J, Yu Y, Lam B, Lianoglou S, Neve RM, Martin S, Settleman J, Yauch RL, Bourgon R. Reproducible pharmacogenomic profiling of cancer cell line panels. Nature. 2016;533:333-7.

9. Cancer Cell Line Encyclopedia C, Genomics of Drug Sensitivity in Cancer C. Pharmacogenomic agreement between two cancer cell line data sets. Nature. 2015;528:84-7.

10. Yang W, Soares J, Greninger P, Edelman EJ, Lightfoot H, Forbes S, Bindal N, Beare D, Smith JA, Thompson IR, et al. Genomics of drug sensitivity in Cancer (GDSC): a resource for therapeutic biomarker discovery in cancer cells. Nucleic Acids Res. 2013;41:D955-61.

11. Barretina J, Caponigro G, Stransky N, Venkatesan K, Margolin AA, Kim S, Wilson CJ, Lehar J, Kryukov GV, Sonkin D, et al. The Cancer cell line encyclopedia enables predictive modelling of anticancer drug sensitivity. Nature. 2012:483:603-7.

12. Aguirre-Gamboa R, Gomez-Rueda H, Martinez-Ledesma E, Martinez-Torteya A, Chacolla-Huaringa R, Rodriguez-Barrientos A, Tamez-Pena JG, Trevino V. SurvExpress: an online biomarker validation tool and database for cancer gene expression data using survival analysis. PLoS One. 2013;8:e74250.

13. Cancer Genome Atlas N. Comprehensive genomic characterization of head and neck squamous cell carcinomas. Nature. 2015;517:576-82.

14. Cancer Genome Atlas Research N. Comprehensive genomic characterization defines human glioblastoma genes and core pathways. Nature. 2008;455: 1061-8.

15. Jin Y, Penning TM. Multiple steps determine the overall rate of the reduction of 5alpha-dihydrotestosterone catalyzed by human type 3 3alpha-hydroxysteroid dehydrogenase: implications for the elimination of androgens. Biochemistry. 2006;45:13054-63.

16. Jez JM, Bennett MJ, Schlegel BP, Lewis M, Penning TM. Comparative anatomy of the aldo-keto reductase superfamily. Biochem J. 1997;326 ( Pt 3: 625-36.

17. Atalla A, Breyer-Pfaff U, Maser E. Purification and characterization of oxidoreductases-catalyzing carbonyl reduction of the tobacco-specific nitrosamine 4-methylnitrosamino-1-(3-pyridyl)-1-butanone (NNK) in human liver cytosol. Xenobiotica. 2000;30:755-69.

18. Chang WM, Lin YF, Su CY, Peng HY, Chang YC, Lai TC, Wu GH, Hsu YM, Chi LH, Hsiao JR, et al. Dysregulation of RUNX2/Activin-a Axis upon miR-376c 
downregulation promotes lymph node metastasis in head and neck squamous cell carcinoma. Cancer Res. 2016;76:7140-50

19. Chang YC, Chi LH, Chang WM, Su CY, Lin YF, Chen CL, Chen MH, Chang PM, Wu AT, Hsiao M. Glucose transporter 4 promotes head and neck squamous cell carcinoma metastasis through the TRIM24-DDX58 axis. J Hematol Oncol. 2017:10:11.

20. Chang WM, Lin YF, Su CY, Peng HY, Chang YC, Hsiao JR, Chen CL, Chang JY, Shieh YS, Hsiao M, Shiah SG. Parathyroid hormone-like hormone is a poor prognosis marker of head and neck Cancer and promotes cell growth via RUNX2 regulation. Sci Rep. 2017;7:41131.

21. Caraux G, Pinloche S. PermutMatrix: a graphical environment to arrange gene expression profiles in optimal linear order. Bioinformatics. 2005;21: 1280-1.

22. El-Kabbani O, Dhagat U, Hara A. Inhibitors of human 20alpha-hydroxysteroid dehydrogenase (AKR1C1). J Steroid Biochem Mol Biol. 2011;125:105-11.

23. Seo DC, Sung JM, Cho HJ, Yi H, Seo KH, Choi IS, Kim DK, Kim JS, El-Aty AA, Shin HC. Gene expression profiling of cancer stem cell in human lung adenocarcinoma A549 cells. Mol Cancer. 2007:6:75.

24. Zhu H, Chang LL, Yan FJ, Hu Y, Zeng CM, Zhou TY, Yuan T, Ying MD, Cao J, He QJ, Yang B. AKR1C1 activates STAT3 to promote the metastasis of nonsmall cell lung Cancer. Theranostics. 2018;8:676-92.

25. Oshimori N, Oristian D, Fuchs E. TGF-beta promotes heterogeneity and drug resistance in squamous cell carcinoma. Cell. 2015;160:963-76.

26. Pal S, Shankar BS, Sainis KB. Cytokines from the tumor microenvironment modulate sirtinol cytotoxicity in A549 lung carcinoma cells. Cytokine. 2013; 64:196-207.

27. West KA, Brognard J, Clark AS, Linnoila IR, Yang X, Swain SM, Harris C, Belinsky S, Dennis PA. Rapid Akt activation by nicotine and a tobacco carcinogen modulates the phenotype of normal human airway epithelial cells. J Clin Invest. 2003;111:81-90.

28. Tsurutani J, Castillo SS, Brognard J, Granville CA, Zhang C, Gills JJ, Sayyah J, Dennis PA. Tobacco components stimulate Akt-dependent proliferation and NFkappaB-dependent survival in lung cancer cells. Carcinogenesis. 2005;26: 1182-95.

29. Vannucchi AM, Kiladjian JJ, Griesshammer M, Masszi T, Durrant S, Passamonti F, Harrison CN, Pane F, Zachee P, Mesa R, et al. Ruxolitinib versus standard therapy for the treatment of polycythemia vera. N Engl J Med. 2015;372:426-35.

30. Plosker GL. Ruxolitinib: a review of its use in patients with myelofibrosis. Drugs. 2015;75:297-308.

31. Forbes LR, Vogel TP, Cooper MA, Castro-Wagner J, Schussler E, Weinacht KG, Plant AS, Su HC, Allenspach EJ, Slatter M, et al. Jakinibs for the treatment of immune dysregulation in patients with gain of function STAT1 or STAT3 mutations. J Allergy Clin Immunol. 2018;142:1665-9.

32. Ajayi S, Becker $H$, Reinhardt $H$, Engelhardt $M$, Zeiser R, von Bubnoff $N$, Wasch R. Ruxolitinib. Recent Results Cancer Res. 2018;212:119-32.

33. Zeng CM, Chang LL, Ying MD, Cao J, He QJ, Zhu H, Yang B. Aldo-keto reductase AKR1C1-AKR1C4: functions, regulation, and intervention for anticancer therapy. Front Pharmacol. 2017;8:119.

34. Deng HB, Parekh HK, Chow KC, Simpkins H. Increased expression of dihydrodiol dehydrogenase induces resistance to cisplatin in human ovarian carcinoma cells. J Biol Chem. 2002;277:15035-43.

35. Matsumoto R, Tsuda M, Yoshida K, Tanino M, Kimura T, Nishihara H, Abe T, Shinohara N, Nonomura K, Tanaka S. Aldo-keto reductase $1 \mathrm{C} 1$ induced by interleukin-1 beta mediates the invasive potential and drug resistance of metastatic bladder cancer cells. Sci Rep. 2016;6:34625.

36. Deng HB, Adikari $M$, Parekh HK, Simpkins H. Ubiquitous induction of resistance to platinum drugs in human ovarian, cervical, germ-cell and lung carcinoma tumor cells overexpressing isoforms 1 and 2 of dihydrodiol dehydrogenase. Cancer Chemother Pharmacol. 2004;54:301-7.

37. Chen J, Adikari M, Pallai R, Parekh HK, Simpkins H. Dihydrodiol dehydrogenases regulate the generation of reactive oxygen species and the development of cisplatin resistance in human ovarian carcinoma cells. Cancer Chemother Pharmacol. 2008;61:979-87.

38. Chen CC, Chu CB, Liu KJ, Huang CY, Chang JY, Pan WY, Chen HH, Cheng $\mathrm{YH}$, Lee $\mathrm{KD}$, Chen MF, et al. Gene expression profiling for analysis acquired oxaliplatin resistant factors in human gastric carcinoma TSGH-S3 cells: the role of IL-6 signaling and Nrf2/AKR1C axis identification. Biochem Pharmacol. 2013;86:872-87.

39. Curtius K, Wright NA, Graham TA. An evolutionary perspective on field cancerization. Nat Rev Cancer. 2018;18:19-32.
40. Hecht SS. Lung carcinogenesis by tobacco smoke. Int J Cancer. 2012;131: 2724-32.

41. Lin RK, Hsieh YS, Lin P, Hsu HS, Chen CY, Tang YA, Lee CF, Wang YC. The tobacco-specific carcinogen NNK induces DNA methyltransferase 1 accumulation and tumor suppressor gene hypermethylation in mice and lung cancer patients. J Clin Invest. 2010;120:521-32.

42. Fuchs SY, Spiegelman VS, Kumar KG. The many faces of beta-TrCP E3 ubiquitin ligases: reflections in the magic mirror of cancer. Oncogene. 2004; 23:2028-36.

43. Geiger JL, Grandis JR, Bauman JE. The STAT3 pathway as a therapeutic target in head and neck cancer: barriers and innovations. Oral Oncol. 2016; $56: 84-92$.

\section{Ready to submit your research? Choose BMC and benefit from:}

- fast, convenient online submission

- thorough peer review by experienced researchers in your field

- rapid publication on acceptance

- support for research data, including large and complex data types

- gold Open Access which fosters wider collaboration and increased citations

- maximum visibility for your research: over $100 \mathrm{M}$ website views per year

At BMC, research is always in progress.

Learn more biomedcentral.com/submissions 